\title{
Advance care planning in people with early cognitive impairment
}

\author{
Kenny Cheong, ${ }^{1}$ Paul Fisher, ${ }^{1,2}$ Jenny Goh, ${ }^{3}$ Lynette $\mathrm{Ng}^{3}$ Hui Mien Koh, ${ }^{4}$ \\ Philip $\mathrm{Yap}^{4}$
}

${ }^{1}$ James Cook University, Singapore

${ }^{2}$ Department of Clinical Psychology, Norwich Medical School, University of East Anglia, UK

${ }^{3}$ Department of Medical Social Service, Khoo Teck Puat Hospital, Singapore ${ }^{4}$ Department of Geriatric Medicine, Khoo Teck Puat Hospital, Singapore

\section{Correspondence to} Dr Philip Yap, Department of Geriatric Medicine, Khoo Teck Puat Hospital, Singapore, 90 Yishun Central, Singapore 768828, Singapore; yap.philip. Ik@alexandrahealth.com.sg

Received 6 January 2014 Revised 31 August 2014 Accepted 6 October 2014 Published Online First 21 October 2014

\section{CrossMark}

\footnotetext{
To cite: Cheong K, Fisher $\mathrm{P}_{\mathrm{t}}$ Goh J, et al. BMJ Supportive \& Palliative Care 2015;5 63-69.
}

\begin{abstract}
Background/aim People with early cognitive impairment $(\mathrm{ECI})$, comprising mild cognitive impairment and early dementia face the risk of diminished mental capacity with progressive disease. Advance care planning (ACP) is advocated as a means to uphold the autonomy of individuals and enable them to express their wishes for the future while they still possess mental capacity. This study aims to explore the perspectives of patients with $E C I$ regarding $A C P$, and in particular, understand their reasons for resistance.
\end{abstract}

Method Consecutive patients undergoing a counselling service for persons with $\mathrm{ECI}$ who fulfilled inclusion criteria (Mini Mental State Examination score $\geq 18$, Global Clinical Dementia Rating $(G C D R)=0.5$ or 1 were recruited. Demographic and clinical data was collected and the detailed documentation in the case records of the counselling sessions was subjected to a thematic analysis. Differences between patients who were willing to engage in ACP and those who declined were also analysed.

Results 93 patients (mean age 76, 60.2\% female) were recruited of which $38.7 \%$ chose to engage further in ACP discussions. GCDR was the only factor that emerged significant on bivariate analysis for willingness to engage in ACP ( $\mathrm{t}(79)$ $=2.191, \mathrm{p}<0.05$, two-tailed) whereby milder $\mathrm{Cl}$ was associated with a greater likelihood of $A C P$ engagement. Among those who declined ACP, three main themes emerged from the thematic analysis. The majority deferred decision-making to their families. Some perceived ACP as irrelevant or unnecessary, and displayed avoidance and denial during ACP discussions.

Conclusions $A$ large proportion of patients with $\mathrm{ECI}$ decline ACP discussions and the reasons are influenced by personal values, coping behaviours and sociocultural norms. These findings have important implications for practice.

\section{INTRODUCTION}

Advance care planning (ACP) is a process that aims to inform and facilitate medical decision-making to reflect patients' values and preferences in the event that they cannot communicate their wishes. ${ }^{1}$ For patients with early cognitive impairment (ECI), which includes persons with mild cognitive impairment (MCI) and earlystage dementia who are susceptible to losing decisional capacity and ability to make healthcare choices, ACP can be beneficial to enable timely decisions about their future. Research suggests positive outcomes for patients with ECI engaging in ACP, including positive effects on quality of life, ${ }^{2}$ maintaining independence for as long as possible, ${ }^{3}$ achieving patient-centred care and maintaining patient autonomy. ${ }^{4}$ However, a recent review paper found limited literature and evidence regarding the best way to approach ACP for people with dementia. ${ }^{5}$

Much remains to be understood about the reasons behind the paradox whereby ACP is arguably beneficial yet underused. ${ }^{67}$ Before attempting to understand the reasons for declining ACP, it is valuable to comprehend the factors leading to ACP completion. To our knowledge, only two studies have explored the reasons people with dementia give for completing $\mathrm{ACP}^{4} \quad 8$ and these include: patients' failing health, encouragement from others, illness or death of others, active planning which was associated with financial and healthcare arrangements and reactive planning which involved patients reacting to an event associated with medical, living situation or financial issue. ${ }^{4} 8$ One study examined prevalence rates and sociodemographic correlates of ACP completion among patients with cognitive impairment. ${ }^{9}$ Results suggested no significant differences in the prevalence of ACP engagement among those with MCI or early Alzheimer's Disease (AD) compared to those with moderate 
to severe $\mathrm{AD}$ and cognitively intact controls. Across all groups, engagement with ACP was associated with increased age, higher education and having a white American ethnicity. ${ }^{9}$

Only two studies have investigated why patients with dementia do not engage in ACP. ${ }^{8}$ The reasons include avoidance, being reluctant to discuss ACP, preferring to leave the decision to others, and not seeing ACP as important or necessary. ${ }^{4} 8$

In Singapore, awareness and use of ACP has been low although its existence in the more limited form of Advanced Medical Directives dates back to $1996 .{ }^{10} 11$ Singaporeans who felt ACP was necessary gave reasons such as 'to lessen the financial burden and emotional burden on loved ones', 'to avoid prolonging suffering', 'respect autonomy and guide patients and family'. ${ }^{11} 12$ Conversely, those who thought ACP was irrelevant remarked: 'it was bad luck to talk about death and a cultural taboo', 'they were unlikely to be in a situation that required one' and 'they were fearful of destroying patient's hope'. Given the move to implement a national ACP programme in the country, ${ }^{13}$ it is timely to conduct studies to better understand the perspectives of patients for whom ACP is deemed important given the diagnosis of a progressive neurodegenerative condition.

The goal of this study is to explore the perspectives of patients with ECI regarding ACP and in particular, their reasons for resistance.

\section{METHOD}

\section{Ethics}

Ethics approval for the study was obtained from the Domain-Specific Review Board of the National Healthcare Group, Singapore and James Cook University Ethics Committee.

\section{Participants and procedure}

The participants comprised consecutive patients diagnosed with MCI or early dementia attending the ECI psycho-education programme of a tertiary hospital memory clinic between 4 October 2012 and 4 June 2013. Patients with ECI fulfilled the following criteria: Mini-Mental State Examination (MMSE) ${ }^{14}$ of $\geq 18^{15}$ and Global Clinical Dementia Rating $(\mathrm{GCDR})^{16}$ of 0.5 to 1.0 and having at least 'fair (3)' to 'good (4)' insight based on the Guidelines for the Rating of Awareness Deficits (GRAD). ${ }^{17}$

During the ECI psycho-education session lasting typically 30-45 min, patients were introduced to ACP by a Medical Social Worker (MSW) with formal training and certification in ACP by Respecting Choices, ${ }^{18}$ an internationally recognised and evidence-based ACP programme. The patient's personal goals, values and beliefs, and their understanding of dementia were explored before the MSW informed them of the rationale and scope of ACP. Patients were asked if they wanted to engage in further ACP discussions and their decisions and the accompanying reasons were documented in prose in the case records by the MSW. These records provided the content for the qualitative analysis. Sociodemographic characteristics such as age, years of education, gender, marital status, ethnicity and religion, and clinical measures were also collected.

\section{MEASURES}

\section{Mini mental state examination}

The MMSE ${ }^{14}$ is a 30 -point test commonly used for cognitive assessment and has been validated in Singapore. It assesses several cognitive domains including arithmetic, memory and orientation. Its inter-rater test reliability $(0.88)$ and test-retest reliability (0.98) are high.

\section{Global clinical dementia rating}

The GCDR scale ${ }^{15}$ assesses global dementia severity based on combined ratings of cognitive, social and functional aspects of the patient by a clinician. A global score is obtained, ranging from 0 to 3 $(0=$ normal, $0.5=$ questionable dementia, $1=$ mild, $2=$ moderate, $3=$ severe dementia).

\section{Guidelines for the rating of awareness deficits}

The GRAD scale ${ }^{1619}$ uses a semistructured interview to assess the patient's degree of awareness by comparing the patient's and caregiver's information about the patient's history. Impaired awareness is defined as the absence of knowledge or recognition of cognitive deficits and its impact. It is rated on a four-point scale, ranging from 4 (intact), 3 (mildly disturbed), 2 (moderately disturbed) to 1 (absent). This test has good inter-rater $(0.73)$ and test-retest reliability $(0.73) .{ }^{20}$

\section{Willingness to engage ACP}

Willingness to engage in further ACP discussions was measured using a dichotomous variable coded 'No' and 'Yes'.

\section{DATA ANALYSIS}

\section{Bivariate analysis}

Using the statistical software SPSS V.16.0 (SPSS Inc, Chicago Illinois, USA), $\chi^{2}$ and independent samples $t$ tests were employed to detect differences in sociodemographic and clinical measures (MMSE, GCDR and GRAD) between patients who were willing or unwilling to engage in further ACP discussions.

\section{Qualitative analysis}

The clinical records of the discussion with the MSW were qualitatively analysed by the first and second authors using a thematic analysis approach, closely following the approach of Braun \& Clarke. ${ }^{21}$ The data for the analysis was managed using NVivo V.9.0 software (QSR International, Victoria, Australia). All data extracts pertaining to the research question were 
given one or more codes to identify pertinent sections. Validity and replicability of the coding process was established. ${ }^{22}$ The first author led the coding of the data which was regularly reviewed by the second author. Differences in coding were resolved through discussion of meaning and constantly returning to the research aim.

After the coding phase, groups of codes with similar meanings were placed together to form overarching subthemes. ${ }^{20}$ Less relevant codes were discarded over time. Subthemes with similar information were clustered together leading to the development of wider main themes. Themes and subthemes were checked against every code to ensure relevance. Consensus was reached regarding minor adjustments to the categorisation of data. Once the themes had been developed, the original data was re-read to confirm their relevance to the source material. Finally, key quotes were identified to represent the themes. On completion of the thematic analysis, the percentage of participants who contributed to a particular theme was tabulated to further demonstrate the validity of the theme.

\section{RESULTS}

\section{Participant characteristics}

Mean age of the patients $(\mathrm{n}=93)$ was 76-years-old, ranging from 58 to 92. Majority were Chinese (90.3\%), females (60.2\%) and married (58.1\%). Buddhists (31.1\%), Christians (25.6\%) and Taoists (21.1\%) comprised the majority and mean MMSE score was $21.31 \pm 3.30$. Table 1 summarises the patients' characteristics.

Only GCDR scores differed significantly between patients who chose to engage in further ACP discussions $(\mathrm{M}=0.66, \mathrm{SD}=0.27)$ and those who declined $(\mathrm{M}=0.81, \mathrm{SD}=0.32 ; \mathrm{t} \quad(79)=2.19, \mathrm{p}<0.05$, twotailed). The magnitude of the difference (mean difference $=0.15,95 \%$ CI: 0.01 to 0.29 ) was modest $\left(\eta^{2}=0.06\right)$.

\section{Willingness to engage in ACP}

Thirty-six (38.7\%) patients agreed to further ACP discussions; the reasons for doing so fell within the categories of welfare, finance and family. Thirty-two (88.9\%) wanted to engage in ACP to plan for their property and

Table 1 Differences in patient variables between those willing to engage in ACP and those not willing

\begin{tabular}{|c|c|c|c|c|}
\hline Variable & $\begin{array}{l}\text { Willing to engage in } \\
\text { ACP }(N=36)\end{array}$ & $\begin{array}{l}\text { Not willing to engage in } \\
\text { ACP }(N=57)\end{array}$ & p Value & $95 \% \mathrm{Cl}$ \\
\hline Mean age & 76.32 & 75.58 & 0.63 & -2.30 to 3.76 \\
\hline Education years & 7.12 & 6.20 & 0.43 & -3.24 to 1.40 \\
\hline MMSE score & 22.00 & 20.88 & 0.11 & -2.51 to 0.26 \\
\hline GRAD score & 3.36 & 3.15 & 0.25 & -0.55 to 0.14 \\
\hline GCDR score & 0.66 & 0.81 & 0.03 & 0.014 to 0.29 \\
\hline Gender & & & 0.43 & - \\
\hline Female & 24 & 32 & & \\
\hline Male & 12 & 25 & & \\
\hline Diagnosis type & & & 1.00 & - \\
\hline $\mathrm{MCl}$ & 9 & 16 & & \\
\hline Dementia & 23 & 41 & & \\
\hline Marital status & & & 0.80 & - \\
\hline Single & 14 & 25 & & \\
\hline Married & 22 & 32 & & \\
\hline Ethnicity & & & 0.99 & - \\
\hline Chinese & 32 & 52 & & \\
\hline Non-Chinese & 4 & 5 & & \\
\hline Religion & & & 0.27 & - \\
\hline Oriental religion & 16 & 31 & & \\
\hline Christianity & 10 & 20 & & \\
\hline Free-thinker & 5 & 2 & & \\
\hline Other religion & 2 & 4 & & \\
\hline
\end{tabular}

Significant values are marked in bold.

For diagnosis type, data were available for 89 participants (96\%). Dementia group consists of patients with Alzheimer's disease, vascular dementia and mixed dementia.

For marital status, single consists of patients who are single, widowed and divorced.

For ethnicity, Non-Chinese consists of patients who are Malays, Indians, Eurasians and other ethnicity.

For religion, data were available only for 90 participants (98\%). Oriental religion consists of patients who are Buddhists and Taoists. Christianity consists Christians and Catholics. Other religion consists Muslims and Hindus.

ACP, advanced care planning; GCDR, Global Clinical Dementia Rating; GRAD, Guidelines for the Rating of Awareness Deficits; MCl, mild cognitive impairment; MMSE, Mini-Mental State Examination. 
assets, 15 (41.7\%) cited planning for personal welfare as a reason, which included medical and social care, and 13 (36.1\%) wanted ACP for their family.

Fifty-seven (61.3\%) patients declined further ACP discussions and qualitative analysis revealed three main themes. These themes and their accompanying subthemes are detailed in table 2 and described below.

Theme 1: acceptance/acquiescence

This comprised three subthemes: leave future to family, leave future to others and leave future to providence and destiny. The patients did not see the need for ACP as they felt secure in having adequate resources to depend on and were open to and accepting of whatever the future held for them, favourable or unfavourable. This theme was present in the accounts of $91.2 \%$ of those who declined ACP.

Majority were comfortable to leave the future to their family, particularly their children, as they assumed they would do what was appropriate. Most of these patients were living with and financially dependent on their children. For example, patient (46) was:

...aware that his memory is deteriorating and will eventually lose mental capacity, [but] he does not see the need to make advance plans for himself...has faith and trust in his children and believes they will make good healthcare and welfare decisions for him.

Some patients were prepared to accept any future arrangements made for them. As regards to future care arrangements, patient (24) expressed that 'if children choose to place him in a nursing home, he will have no say'. Patients who were single, without close relatives displayed little worry about having to depend on more distant relations. For instance, of patient (56), the MSW wrote:

If she cannot walk well, she plans to rest in bed more at home and wait for niece's family to buy meals for her. She leaves long-term planning to her niece's family as she does not have the resources to plan for herself and trusts them to make plans for her.

Patients were also willing to leave the future to providence and destiny. Patient (80) stated that she would "leave everything to God and cope through her strong faith and daily prayers". Similarly, patient (59) reported that he will "leave decisions to his son, fate and destiny".

Table 2 Themes and subthemes

\begin{tabular}{lll}
\hline Acceptance/acquiescence & $\begin{array}{l}\text { Irrelevant/ } \\
\text { unnecessary }\end{array}$ & $\begin{array}{l}\text { Avoidance/ } \\
\text { denial }\end{array}$ \\
\hline $\begin{array}{l}\text { Leave future to family } \\
\text { Leave future to providence/destiny }\end{array}$ & $\begin{array}{l}\text { Planning 'done' } \\
\text { Lack of finances }\end{array}$ & $\begin{array}{l}\text { Avoidance } \\
\text { Uncertainty/ } \\
\text { insecurity }\end{array}$ \\
$\begin{array}{l}\text { Leave future to others (others refer } \\
\text { to friends and trusted associates) }\end{array}$ & Lack of support & \begin{tabular}{l} 
Denial \\
\hline
\end{tabular}
\end{tabular}

Theme 2: ACP perceived as irrelevant or unnecessary

The second theme, endorsed by 45 patients comprised the subthemes: planning 'done', lack of finances and lack of support. Despite acknowledging the importance of planning for the future, patients did not see the need to do so. Furthermore, some failed to understand the relevance of ACP and its immediacy.

About half of these patients felt that completing ACP was unnecessary as they had 'completed' their planning or engaged in informal planning, which usually consisted of verbally informing close ones about end-of-life decisions. Many had initiated financial planning by creating joint savings accounts or completing a will. Patient (83) told the MSW that "she has a joint savings account with one of her sons and done up a will to bequeath the flat to her children...no one can touch the house when she is alive".

For some patients ACP was considered irrelevant due to lack of finances or being financially dependent on family. Patient (53) thought that "it is important to complete ACP but thinks he does not have much assets to worry", while patient (51) reported that "she has little property and finances, so no immediate need [for ACP]".

The third subtheme revolved around lack of support. Some patients were not keen to discuss ACP due to a lack of trust in their family. Patient (54) reported he was "not keen to consider ACP as he has reservations and lack of trust over wife and children's abilities to follow his wishes". Family members may also influence non-engagement in ACP discussions in two other ways: (1) agreeing with the patient that ACP is irrelevant and (2) dismissing patients' end-of-life plans. Pertaining to the former, the son of patient 7 explained that the "family is supportive and understands patient's wishes, thus agreeing that ACP is not necessary". As regards the latter, patient (42) shared that her plans to "split her savings and have a sea-burial" were dismissed by her children who showed little interest in what she had expressed.

\section{Theme 3: avoidance and denial}

The third theme comprised three subthemes: avoidance, uncertainty and insecurity, and denial. This theme highlights coping strategies and defence mechanisms initiated by patients when being broached with the topic of planning for end of life. The accounts of 40 patients (70.2\%) who declined ACP discussions showed facets of either avoidance or denial. Avoidance was demonstrated in active and passive ways. For instance, when discussing future plans about finances, patient (14) 'became rather evasive...showing signs of discomfort', whereas patient (43) 'got impatient and asked to leave session to go to the toilet'. Those who showed passive avoidance were contented to 'live by the day' (patient (32)) or 'face it when the situation arises' (patient (88)). 
The apparent uncertainty and insecurity about the implications of ACP also contributed to avoidance coping. Patient (3) shared that "she is wary about doing (advance directive) as she is worried that it will cause conflict between her two sons", whereas patient (75) expressed "she does not want her children to be unhappy that she is 'playing favorites' by appointing certain children as 'done".

Finally, the strong levels of denial in some patients precluded deeper conversations about ACP. Patient (11) reported that, "he believes strongly that his forgetfulness is solely due to his inactive lifestyle which can be easily 'reversed' once he has better access to a (conducive) environment and resumes (past) activities". Apart from misconstruing dementia can be overcome, some perceived themselves as healthy with claims of being "currently far away from (dementia) and still very clear-minded" (patient ((73)).

\section{DISCUSSION}

To our knowledge, this is the first study investigating reasons for declining ACP discussions among patients with ECI to employ a qualitative methodology. The results suggest the overall willingness to engage in further ACP conversations is modest at $38.7 \%$. The findings are consistent with a previous local study ${ }^{10}$ which found that opinions towards ACP have remained static throughout the years.

The only difference found between patients who declined or accepted ACP was dementia severity by GCDR scores. This is in contrast to previous research that found age, education level and ethnicity, and not cognitive function to be associated with completion of ACP. ${ }^{9}$ However, the current study investigated interest in further ACP discussions whereas previous research examined actual completion rates. More advanced CI was associated with lower acceptance of ACP. Earlier studies posit there is a point at which cognition decreases so critically that ACP can no longer be meaningfully undertaken. ${ }^{5}$ Our findings add to the evidence that it is pertinent to engage patients with CI early for successful engagement in ACP.

The reasons for pursuing ACP were consistent with those in extant literature ${ }^{4}{ }^{11}{ }^{12}$; personal welfare, family and financial matters. Planning for finances was foremost and comparable in importance to a previous Singapore study ${ }^{11}$ which involved a younger sample with presumably better education and knowledge, factors that are generally associated with higher uptake of ACP. Younger participants are also more likely to have young families, which underscores the importance of planning for one's family and welfare. Nonetheless, even in our older cohort of patients with ECI, our findings emphasise the need to educate the public that ACP goes beyond financial arrangements and entails planning for healthcare and other end-of-life matters.
A high proportion of patients who declined ACP adopted a less proactive and more acquiescent stance, similar to findings in previous studies, ${ }^{48}$ and the predominantly Chinese patients in our study could in part explain the findings. In East Asian culture, Confucianism and the high importance placed on an individual's relations with family and society have critical influence on end-of-life decisions. ${ }^{12}$ Within the traditional Asian context, patients may choose to leave decision-making to their children. Interestingly, although leaving the future to God was elicited as a subtheme, religion was not found to be significantly associated with willingness to engage in ACP discussions. Further research is thus necessary to examine the effects of religion on ACP completion.

A significant proportion of the patients deemed ACP irrelevant or unnecessary as they had undertaken informal planning in the form of writing a will or creating joint bank accounts with particular family members. As such, these patients perceived planning to have been 'completed'. This highlights the lack of knowledge about ACP in our patients ${ }^{10} 11$ and plausibly in the general public whereby the difference between formulating a will and ACP appears unclear. The former is effected only on demise while the latter is operationalised while the person is still alive but lacking mental capacity. The value of a formal ACP in being medically binding and legally legitimate, in the form of a lasting power of attorney, needs emphasis. More systematised efforts to explain the purpose of ACP and appointing healthcare proxies is certainly needed.

The subtheme, lack of support, has been reported by Schickedanz et $a l^{23}$; however, in this study the reasons appear more complex. Despite the presence of their families, some patients still struggle to make decisions on whom to depend on or may lack someone they can entrust the future to. Furthermore, family members are not always supportive of ACP engagement or may adopt a dismissive attitude to patients' end-of-life decisions. Speaking about death and dying has traditionally been a cultural taboo among Chinese. ${ }^{11} 12$ This uniquely Asian phenomenon can present obstacles to ACP and thus deserves further research to explore ways to overcome this sociocultural barrier.

Consistent with previous research, ${ }^{4} 8$ many patients appeared unable to contemplate end-of-life issues and avoided discussions around the subject. This could indicate their inability or unwillingness to admit to the dementia diagnosis or the prospect of losing mental capacity, and tended to build a defensive reaction to the topic. Cognitive deficits could provide an explanation, however, there is also a predilection for patients to normalise their deficits especially in a society that still lacks understanding of dementia as evidenced by a recent publication. ${ }^{24}$ Conversely, some patients who did not refrain from ACP discussions 
expressed uncertainty and anxiety as they were concerned about the consequences of formulating advance directives. This perspective has been cited as one of the limitations of $\mathrm{ACP}^{25}{ }^{26}$ and might suggest patients doubt ACP's effectiveness in conveying their wishes. As the Hastings Centre Report ${ }^{27}$ posits, it is already hard to make decisions about contemporary illnesses, what more for an unspecifiable future?

Taken together, the results show patients have varying levels of readiness for ACP, and many encounter difficulties at the precontemplation and contemplation steps. ${ }^{22}$ As these difficulties are often experienced at the early stages of the ACP process, intervention by way of education and counselling to empower patients with more knowledge and alleviate their concerns can help. ACP conversations should be initiated early in the continuum of cognitive decline as ACP acceptance is higher in the milder stages of cognitive impairment.

The implications of the findings go beyond patients with CI and may be pertinent for the general public as many of the factors unveiled pertain to personal values, coping behaviours and sociocultural norms, over and above barriers imposed by $\mathrm{CI}$ alone. Importantly, family-centred decision-making is more prevalent than autonomous decision-making in Asian cultures ${ }^{28}$ and 'leave it to the family' is a common refrain proffered against completion of ACP. Understanding these issues is crucial for policymakers, healthcare providers and researchers in designing stepspecific interventions to help patients overcome the barriers, engage better in ACP and move towards completing advance care directives. ${ }^{22}$

A few limitations of this study are noteworthy. First, the findings may not be readily applicable to other populations as our sample comprised mostly Chinese from a tertiary hospital in Singapore. Second, the use of MSW's reports for qualitative analysis instead of verbatim interview transcripts of actual patient encounters can limit the ability to adequately capture the complexities and nuances of patients' perspectives on ACP. It may also contain the MSW's personal interpretation and consequently predispose to reporting bias. However, efforts had been made to ensure consistency in reporting which emphasised careful reporting of the patients' responses in prose form.

Finally, the study only captures the patient's willingness to engage in ACP discussions at a single time point and does not preclude the possibility that some who decline may subsequently change their minds. As individuals' values and beliefs are fluid and may change over time, ${ }^{29}$ the initial ACP discussion could be the start of a series of conversations which may eventually lead to successful completion of advance care plans. As ACP is an ongoing and dynamic process, ${ }^{1}$ it would be instructive to conduct longitudinal follow-up studies to see how many patients eventually formulate ACPs.

\section{CONCLUSION}

This study shows the majority of patients with ECI (61.3\%) are unwilling to engage in ACP discussions and the reasons for declining are more complex than previous research suggested. With the use of qualitative methods, new themes that reflect personal values, coping behaviours and sociocultural norms have emerged. These findings can be relevant for those without cognitive impairment as well. Discussions on ACP should be initiated as early as possible and it is hoped that a deeper understanding of patients' perspectives on ACP can guide interventions to help patients overcome the barriers and improve advance directives completion rates.

Acknowledgements The authors would like to thank the patients who attended the counselling sessions and the nurses who helped collate the information for the study.

Contributors KC planned the study, carried out the literature review, data analysis and interpretation and drafted the manuscript. PF contributed to planned the study, assisted in the data analysis, interpreted the results and revised the manuscript JG, LN and HMK collected the data, interpreted the results and contributed to the manuscript. PY conceived the research idea, planned the study, interpreted the results and revised the manuscript. PY is responsible for the overall content as guarantor. All authors confirmed the final version of the manuscript.

Competing interests None.

Ethics approval National Healthcare Group, Singapore.

Provenance and peer review Not commissioned; externally peer reviewed.

\section{REFERENCES}

1 Starks H, Vig EK, Pearlman RA. Advance care planning. In: Emanuel LL, Librach SL, eds. Palliative care: core skills and clinical competencies. Philadelphia: Saunders-Elsevier, 2007:270-83.

2 Menne HL, Judge KS, Whitlatch CJ. Predictors of quality of life for individuals with dementia: implications for intervention. Dementia 2009;8:543-60.

3 Hayden C, Boaz A, Taylor F. Attitudes and aspirations of older people: a qualitative study. DSS Research Report No. 102. London: Stationery Office, 1999.

4 Hirschman KB, Kapo JM, Karlawish JHT. Identifying the factors that facilitate or hinder advance planning by persons with dementia. Alzheimer Dis Assoc Disord 2008;22:293-8.

5 Dening KH, Jones L, Sampson EL. Advance care planning for people with dementia: a review. Int Psychogeriatr 2011;23:1535-51.

6 Gamble ER, McDonald PJ, Lichstein PR. Knowledge, attitudes, and behavior of elderly persons regarding living wills. Arch Intern Med 1991;151:277-80.

7 Silveira MJ, Kim SY, Langa KM. Advance directives and outcomes of surrogate decision making before death. N Engl J Med 2010;362:1211-18.

8 Black BS, Fogarty LA, Phillips H, et al. Surrogate decision makers' understanding of dementia patients' prior wishes for End-of-Life care. J Aging Health 2009;21:627-50.

9 Lingler JH, Hirschman KB, Garand L, et al. Frequency and correlates of advanced planning among cognitively impaired older adults. Am J Geriatr Psychiatry 2008;16:643-9. 
10 Low JA, Ng WC, Yap KB, et al. End-of-life issues-preferences and choices of a group of elderly Chinese subjects attending a day care centre in Singapore. Ann Acad Med Singapore 2000;29:50-6.

11 Tay M, Chia SE, \& Sng J. Knowledge, attitudes and practices of the advance medical directive in a residential estate in Singapore. Ann Acad Med Singapore 2010;39:424-8.

$12 \mathrm{Ng} \mathrm{R}$, Chan S, Ng TW, et al. An exploratory study of the knowledge, attitudes and perceptions of advance care planning in family caregivers of patients with advanced illness in Singapore. BMJ Support Palliat Care 2013;3:343-8.

13 Chung I, Wong C, Oh C, et al. Implementing a national advance care planning (ACP) programme in Singapore. BMJ Support Palliat Care 2013;3:256-7.

14 Folstein MF, Folstein SE, McHugh PR. "Mini-mental state”. A practical method for grading the cognitive state of patients for the clinician. J Psychiatr Res 1975;12:189-98.

15 Feng L, Chong MS, Lim WS, et al. The modified mini-mental state examination test: normative data for Singapore Chinese older adults and its performance in detecting early cognitive impairment. Singapore Med J 2012;53:458-62.

16 Hughes CP, Berg L, Danziger WL, et al. A new clinical scale for the staging of dementia. Br J Psychiatry 1982;140:566-72.

17 Verhey FRJ, Rozentaal N, Ponds RWHM, et al. Dementia, awareness and depression. Int J Geriatr Psychiatry 1993;8:851-6.

18 Gundersen Health System. Respecting choices: advance care planning. http://www.gundersenhealth.org/respecting-choices (accessed 30 December 2013).

19 Zanetti O, Vallotti B, Frisoni GB, et al. Insight in dementia: when does it occur? Evidence for a nonlinear relationship between insight and cognitive status. J Gerontol B Psychol Sci Soc Sci 1999;54B:100-6.

20 Vallotti B, Zanetti O, Bianchetti A, et al. L'insight nel paziente demente: riproducibilita di due strumenti di valutazione [Reproducibility of two scales to rate the insight in demented patients]. J Gerontol 1997;45:341-5.

21 Braun V, Clarke V. Using thematic analysis in psychology. Qual Res Psychol 2006;3:77-101.

22 Firth H, Gleeson K. Clothing and embodiment: men managing body image and appearance. Psychol Men Masc 2004;5:40-8.

23 Schickedanz AD, Schillinger D, Landefeld CS, et al. A clinical framework for improving the advance care planning process: start with patient's self-identified barriers. J Am Geriatr Soc 2009;57:31-9.

24 Tan WJ, Hong SI, Luo N, et al. The lay public's understanding and perception of dementia in a developed Asian nation. Dementia Geriatr Cogn Disord Extra 2012;2:433-44.

25 Doukas DJ, Hardwig J. Using the family covenant in planning end-of-life care: obligations and promises of patients, families, and physicians. J Am Geriatr Soc 2003;51:1155-8.

26 Fagerlin A, Ditto PH, Danks JH, et al. Projection in surrogate decisions about life-sustaining medical treatments. Health Psychol 2001;20:166-75.

27 Fagerlin A, Schneider CE. Enough: failure of the living will. Hastings Cent Rep 2004;34:30-42.

28 Chong JA, Quah YL, Yang GM, et al. Patient and family involvement in decision making for management of cancer patients at a centre in Singapore. BMJ Support Palliat Care Published Online First: 3rd Jan 2013. doi:10.1136/ bmjspcare-2012-000323.

$29 \mathrm{Ng}$ HPR. Advance care planning: let's talk about your preferences for care at the end of life. Singapore Fam Physician 2009;35:93-9. 